\title{
Influence of initial imperfection on stability of axially compressed column in electrostatic precipitator casing*
}

\author{
Jing-Tong Zhao, Hai-Feng Qian, Li-Cheng Pan and Deng-Feng Wang \\ School of Environment and Civil Engineering, \\ Jiangnan University, \\ Wuxi 214122, Chinat \\ †E-mail:2895364237@qq.com \\ www.university_jiangnan.edu
}

\begin{abstract}
In the making and erection process of wall-column structural system of electrostatic precipitator casing, the imperfection will be produced inevitably and influence the stability of the column. It's necessary for numerical simulation model that the imperfection is taken into account when the numerical investigations are carried out into the stability of column. Based on the configurations of profiled steel sheet-rectangular tube column structural systems of practical electrostatic precipitator casings, the influences of initial geometrical imperfections on the stability of columns subjected to axial compression were investigated by the nonlinear finite element method. The results show that when the profiled steel sheet groove direction arranged perpendicular to the column, the most unfavorable initial geometrical imperfection shape is the initial flexural deformation of column section, the most unfavorable initial geometrical imperfection shape is the initial flexural deformation of column section, the most unfavorable and maximum initial geometrical imperfection located in the column apical region where has the high axial force. When setting up the finite element models for the buckling of axially compressed column of casing, in order to fully consider the unfavorable influence of initial geometrical imperfections, it's necessary to introduce the entire flexural defect mode which occurred in the column apical region.
\end{abstract}

Keywords: Electrostatic Precipitator; profiled steel sheet; rectangular tube; column; initial imperfection; stability; finite element analysis.

\section{Introduction}

Precipitator is an important environmental equipment for pollution control, which is widely used in thermal power, metallurgy, building materials and chemical industries to eliminate dust. The researches about the precipitator were focus on its process, but only a few on its bearing mechanism of the supporting

\footnotetext{
${ }^{*}$ This work is supported by Project(50778102) supported by the National Natural Science Foundation of China; Project(BK20130149) supported by the Natural Science Foundation of Jiangsu Province, China
} 
structure. Casing wall is the most important part of the precipitator, which is used as the side enclosure structure with $\mathrm{H}$ shaped column. The casing wall being made of stiffened steel plates is connected with columns by continuous components. The wall-column structural system under load is shown in Figure1.

Domestic and foreign scholars have made some research results about the stressed skin structure. Davies and Bryan conducted a large number of tests of the theoretical research, analyzed and put forward the determination by the formula for the calculation of the stressed skin shear flexibility and strength[1]. The research of Wright et al showed that the connection type and arrangement between the diaphragm and the supporting frame have important influence on the shear capacity of the skin plate[2].Lucas et al. studied the cold-formed purlin-sheeting calculation model. One was an entire model with purlins and sheeting, the other is a simplified model with only purlins. In the simplified model, the shear and rotational stiffness of the sheeting was simulated by using spring, which connected the edge of the purlins and the sheeting. By setting the reasonable spring parameters, the responding of two kinds of models and experiments got similar results[3,4].

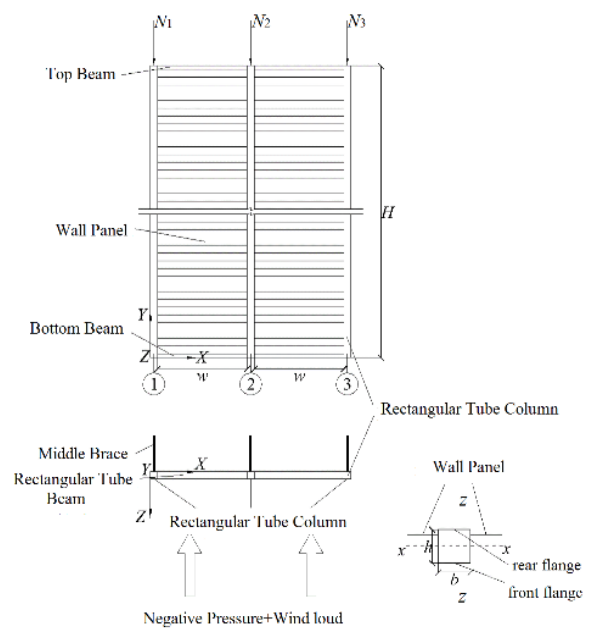

Fig. 1. wall-column structural system

\section{The Influence of Initial Geometric Imperfections on the Stability of the Axial Compression of the Column}

To study the influence regular pattern of the stability, the column is induced to instability. Meanwhile, the effect of different types of initial geometrical imperfections on the stability of the column is studied. The paper modeled the multiple column initial geometric imperfection, to study its bearing capacity, 
instability modes and explore the most unfavorable initial geometric imperfection.

\subsection{Buckling mechanism of the perfect structure}

The wall beam, wall and column is connected closely, which can share part of the load for the column, high column axial force area more concentrated in the vicinity of the capitals, and axial compression downward decay faster. The loaddisplacement curve of models with different geometrical imperfection modes are shown in Figure2, plotted by maximum deformation out of column plane on the horizontal axis and axial load on the vertical.

In the perfect structure, column subjected to axial compression eventually occurs bending instability about the $\mathrm{x}$ axis and the maximum bending deformation on the column is located at the head of the column below one third, direction is the plus direction at $\mathrm{Z}$.

Because both sides of the square tube column have twists and turns board panel connection. When the column subjected to axial pressure wallboard for the column to share part of the pressure, so the column section stress distribution is not uniformed, the flange compressive force is small which near the wall plate, and the opposite one is comparably larger, the column has bending moment. The failure of structural is due to a large scope of yield in the column apical range, which does not has further flexural capacity.

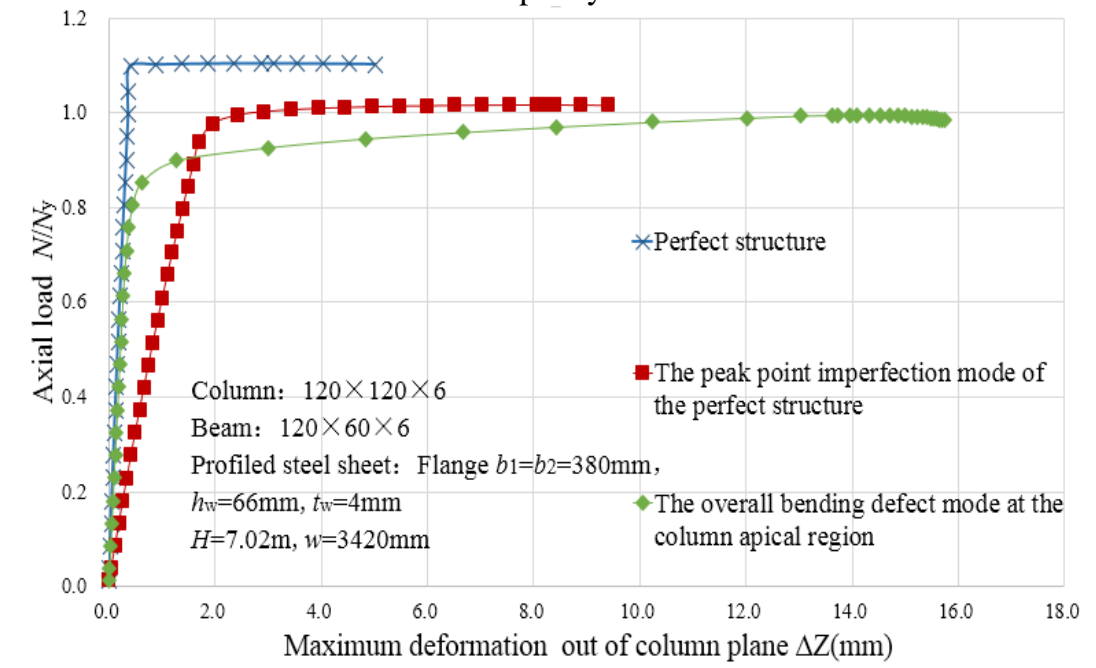

Fig. 2. Comparison among load-displacement curves of models with different geometrical imperfection modes 


\subsection{The influence of the perfect structure peak point imperfection mode.}

The deformation mode of the load to the maximum load of the perfect structure as the peak points of the perfect structure's deformation of imperfection mode, the imperfection amplitude delta $\delta_{0}$ take $H / 1000$. Calculate the perfect structure with the peak points of the structure deformation of imperfection modes in bearing capacity, the load displacement of curve at this time is shown in Figure 2 , the ultimate bearing capacity is $8 \%$ lower than the value of the perfect structure. The buckling mode of square tube column with perfect structural extreme point deformation is similar to the perfect structure. With the initial bending, the initial structure stiffness will decrease and the ultimate bearing capacity of column bending deformation is significantly greater than that of the perfect structure.

\subsection{The influence of the top section of the column with the initial overall bending imperfection}

Due to the column of the perfect structure shows an overall bending-buckling trend about the $\mathrm{x}$ axis, infer that the column may be sensitive to overall bendingbuckling. Therefore, build the column with overall bending initial geometric imperfections. Build the initial overall bending deformation about the $\mathrm{x}$ axis at the top area of the middle column, the amplitude value of the initial geometric deformation $\delta_{0}$ takes $H / 1000$.

According to the load-displacement curves of Figure 2 can be seen, the structure stability bearing capacity of overall bending imperfection at the top of the column are $9.87 \%$ lower than the perfect structure. The deformation at the $\mathrm{z}$ direction when structure reach the stability bearing capacity of the column as shown in Figure 3 and the maximum deformation at direction $\mathrm{Z}$ when the column buckling is at the maximum deformation of the bending imperfection mode. Despite of the overall bending deformation, the walls of the tube are local buckling, which are local sunken on the front and buckling on two sides. The local buckling deformation of walls on the column increases, therefore, a part of section of the column will gradually out of work. When the section of the column from one side of twists in compression yield occurs on a large area, the structure will lost further loading capability. 


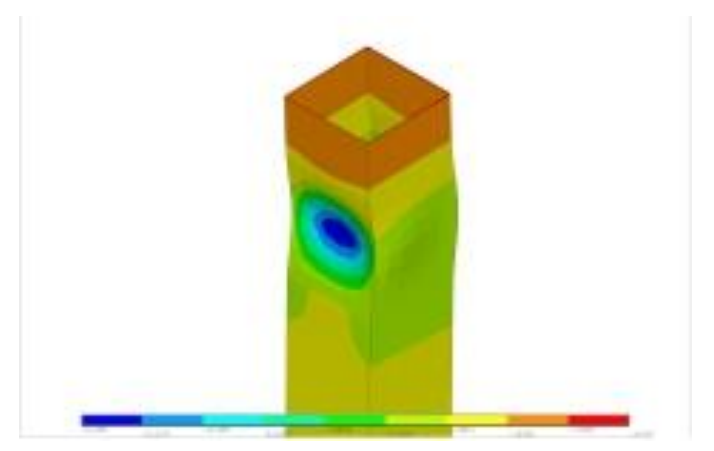

Fig. 3. Distribution of $Z$ to the deformation of ultimate bearing capacity of the whole bending imperfection structure with the top of the column (mm)

\section{Conclusion}

Based on the configurations of wall-column structural systems of practical electrostatic precipitator casings, the influences of initial geometrical imperfections on the stability of columns subjected to axial compression were investigated by the nonlinear finite element method, get the conclusions as follow:

(1)Because of the twists and turns in the wall of stressed skin effect, the column does not occur bending-buckling inside the wall plate or twist buckling, appearselastic-plastic bending-buckling close to the column area below the wall out of plane.

(2)The maximum initial geometric deformation position in the high axial pressure region is most unfavorable to column stability.

(3)The axial compression stability of wall-column is moresensitive to the initial geometric deformation pattern as the overall bending imperfection mode at the top of the column.

\section{References}

1. Davies J M, Bryan E R. Manual of Stressed Skin Diaphragm Design [M]. London: Granada Publishing, 1982.

2. Wright Howard D., Hossain K. M. Anwar. In-plain shear behavior of profiled steel sheeting [J]. Thin-walled Structures, 1997, 29: 79-100.

3. R M Lucas, F G AAlbermani, S Kitipornchai. Modelling of cold-formed purlin-sheeting systems-Part1: Full Model [J]. Thin-Walled Structures, 1997, 27(3): 223-243.

4. R M Lucas, F G AAlbermani, S Kitipornchai. Modelling of cold-formed purlin-sheeting systems-Part2: Simplified Model [J]. Thin-Walled Structures, 1997, 27(4): 263-286. 